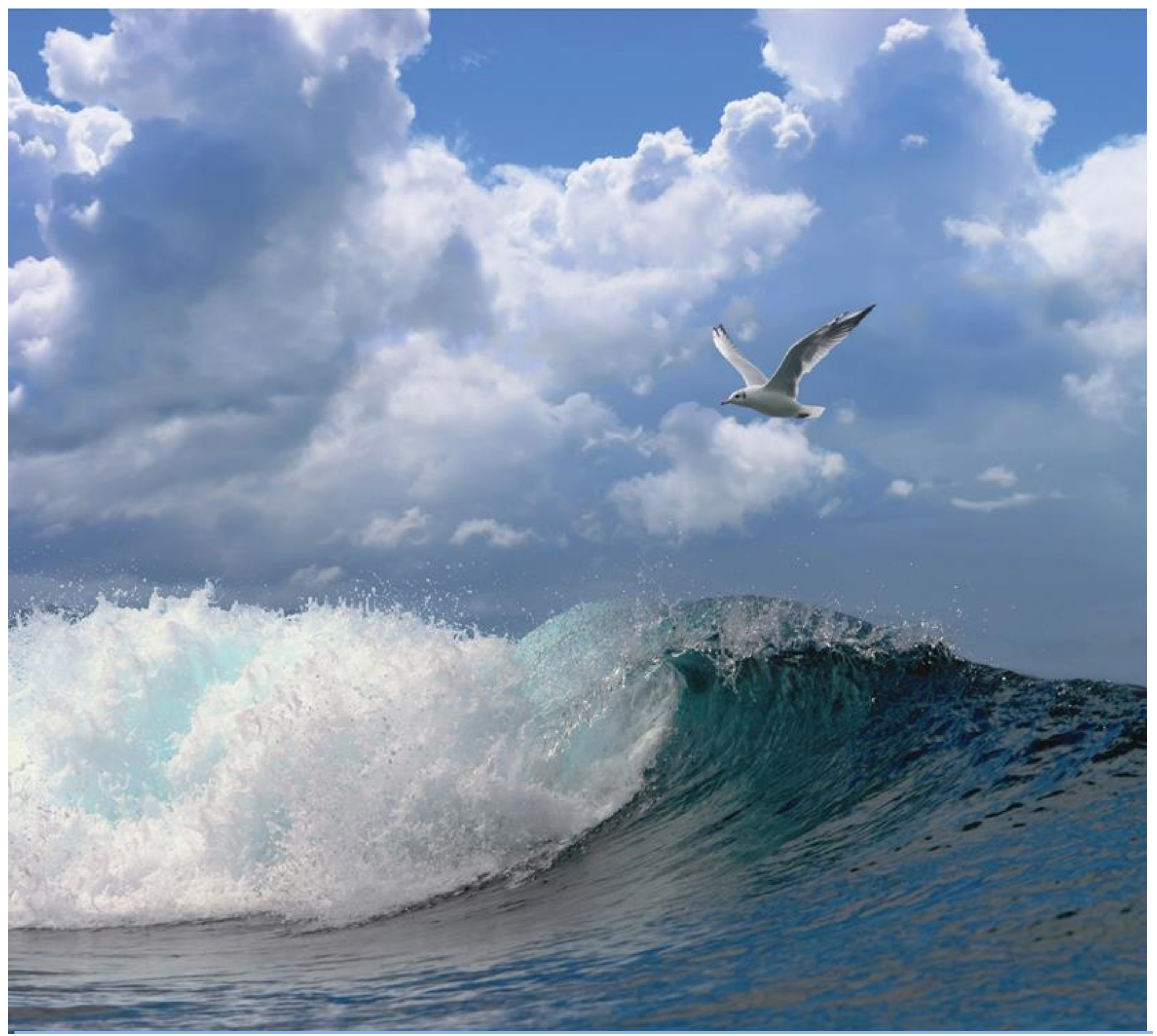

\title{
Bestandsopname van mosselen op mosselkweekpercelen in de Waddenzee in februari 2018
}




\section{Bestandsopname van mosselen op mosselkweekpercelen in de Waddenzee in februari 2018}

Auteur(s): Jacob Capelle, Marnix van Stralen

Publicatiedatum: 17 april 2018

Wageningen Marine Research Yerseke, april 2018 
Jacob J. Capelle, Marnix, R. van Stralen, 2018. Bestandsopname van mosselen op mosselkweekpercelen in de Waddenzee in februari 2018. Wageningen Marine Research Wageningen UR (University \& Research centre), Wageningen Marine Research rapport C027/18. 22 blz.

Keywords: mosselbestand, mosselkweek, Waddenzee

Opdrachtgever: Ministerie van LNV en PO Mosselcultuur

Dit rapport is gratis te downloaden van https://doi.org/10.18174/446980

Wageningen Marine Research verstrekt geen gedrukte exemplaren van rapporten.

Wageningen Marine Research Wageningen UR is ISO 9001:2008 gecertificeerd.

(C) 2018 Wageningen Marine Research Wageningen UR

Wageningen Marine Research, onderdeel van Stichting Wageningen Research KvK nr. 09098104,

IMARES BTW nr. NL 8113.83.696.B16. Code BIC/SWIFT address: RABONL2U IBAN code: NL 73 RABO 0373599285
De Directie van Wageningen Marine Research is niet aansprakelijk voor gevolgschade, noch voor schade welke voortvloeit uit toepassingen van de resultaten van werkzaamheden of andere gegevens verkregen van Wageningen Marine Research opdrachtgever vrijwaart Wageningen Marine Research van aanspraken van derden in verband met deze toepassing.

Dit rapport is vervaardigd op verzoek van de opdrachtgever hierboven aangegeven en is zijn eigendom. Niets uit dit rapport mag weergegeven en/of gepubliceerd worden, gefotokopieerd of op enige andere manier gebruikt worden zonder schriftelijke toestemming van de opdrachtgever. 


\section{Inhoud}

Samenvatting

2 Methode $\quad 6$

$\begin{array}{lll}2.1 & \text { Bemonstering } & 6\end{array}$

2.2 Berekeningen 6

$\begin{array}{llr}3 & \text { Resultaten } & 8\end{array}$

3.1 Mosselbestand $\quad 8$

3.2 Zeesterren en krabben $\quad 10$

$4 \quad$ Discussie en conclusie $\quad 13$

$\begin{array}{llr}5 & \text { Kwaliteitsborging } & 14\end{array}$

$\begin{array}{lr}\text { Literatuur } & 15\end{array}$

$\begin{array}{lr}\text { Verantwoording } & 16\end{array}$

$\begin{array}{lr}\text { Bijlage } 1 \text { werkvoorschrift monstername } & 17\end{array}$

$\begin{array}{lr}\text { Bijlage } 2 \text { Kaarten mosseldichtheid per grootteklasse } & 18\end{array}$ 


\section{Samenvatting}

Een van de uitgangspunten bij de mosselzaadvisserij is dat de omvang van het mosselbestand in de Waddenzee en daarmee het voedselaanbod voor vogels niet minder is dan in een situatie dat niet wordt gekweekt en gevist. Dat betekent dat in het najaar een zekere hoeveelheid mosselen op de kweekpercelen in de Waddenzee aanwezig dient te zijn. Voor 2017 is deze hoeveelheid vastgesteld op 48 miljoen (peildatum 1 december). Na de voorjaarsvisserij wordt met een bestandsopname een schatting gemaakt van het bestand op de kweekpercelen (de zogenaamde 'starthoeveelheid') en wordt vervolgens bijgehouden hoeveel mosselen afgevoerd worden en hoeveel mosselen erbij komen. Een tweede bestandsopname is bedoeld om te kunnen valideren of de eerder genoemde hoeveelheid mosselen aan het begin van de winter inderdaad op de percelen aanwezig was. In voorliggende rapportage wordt de bestandsopname op de percelen in de winter van 2017/2018 gerapporteerd. Hiertoe zijn alle kweekpercelen in de Waddenzee waar mosselen verwacht worden in de winter van $2017 / 2018$ bemonsterd. Het totale bestand op de percelen in eind januari-begin februari is geschat op $\mathbf{5 0 , 4}$ miljoen $\mathbf{k g}$. Op basis van deze schatting kan geconcludeerd worden dat de benodigde minimale hoeveelheid mosselen op 1 december 2017 op de percelen aanwezig was. 


\section{$1 \quad$ Inleiding}

Eén van de uitgangspunten voor de mosselzaadvisserij is dat het geheel van vissen, kweek en afvoer van mosselen naar Zeeland ('VKA') niet leidt tot minder mosselen in de Waddenzee en daarmee tot minder voedsel voor overwinterende vogels dan in een situatie waarin niet zou worden gekweekt en gevist. De achtergronden hiervan zijn na te lezen in de passende beoordeling voor de mosselzaadvisserij (Van Stralen, 2015) en de NB-wet vergunning die voor de periode 2015-2017 door het ministerie van LNV voor deze visserij is verleend $(E Z, 2014)$.

Dit uitgangspunt betekent dat er in het najaar een zekere minimale hoeveelheid mosselen op de percelen aanwezig moet zijn, wat als voedsel voor overwinterende vogels beschikbaar is. Om dat te borgen wordt na de voorjaarsvisserij met een bestandsopname een schatting gemaakt van het bestand op de kweekpercelen (de zogenaamde 'starthoeveelheid') vervolgens wordt er bijgehouden hoeveel mosselen naar Zeeland worden afgevoerd en hoeveel mosselen erbij komen afkomstig uit MZI's en andere bronnen (bijvoorbeeld door 'Zuid-Noord' transporten, d.w.z. transporten van mosselen uit Zeeland naar de Waddenzee).

Als onderdeel van de vergunningverlening voor de mosselzaadvisserij in het voorjaar van 2017 is berekend dat in het najaar van 2017 (ijkmoment 1 december) een bestand van minimaal 48 miljoen kg netto (mosselen zonder tarra) aanwezig dient te zijn (van Stralen, 2017).

Het mosselbestand op de percelen na de voorjaarsvisserij van 2017 is geïnventariseerd in de periode juli - augustus 2017. Dit resulteerde in een schatting van het mosselbestand op de percelen van 119 miljoen kg netto. De tweede bestandsopname in de winter van 2017/2018, beschreven in voorliggend rapport, is bedoeld om te kunnen valideren of de eerder genoemde minimale hoeveelheid mosselen van 48 miljoen $\mathrm{kg}$ netto aan het begin van de winter inderdaad op de percelen aanwezig was. Het onderzoek is begeleid en gerapporteerd door Wageningen Marine Research, met als opdrachtgever het ministerie van LNV en de PO Mosselcultuur. 


\section{Methode}

\section{$2.1 \quad$ Bemonstering}

Alle kweekpercelen in de Waddenzee waar mosselen verwacht worden zijn in de winter van 2017/2018 bemonsterd. De bestandsopname is uitgevoerd zoals beschreven is in Van Stralen (2013). Hiervoor zijn bemonsteringsstations volgens een regelmatig grid over de kweekpercelen verdeeld. De bemonsteringsstations liggen in noordelijke en oostelijke richting 0,2 nautische minuten van elkaar, overeenkomend met een gridceloppervlakte van 8,26 ha. Kweekpercelen of gedeelten van kweekpercelen die in de winter niet voor mosselkweek gebruikt worden zijn hierbij uitgesloten, waarbij uitgegaan is van:

(1) De algemene ervaringskennis van buitendienst medewerkers van de Waddenunit van het Ministerie van EZ en in het bijzonder van de heer Nico Laros over de geschiktheid en daarmee het gebruik van de mosselpercelen.

(2) De bemonsteringen van de percelen met een mosselkor zoals die periodiek vanaf de inspectieschepen "Asterias" en "Phoca" worden uitgevoerd.

(3) Recente gegevens over het uitzaaien van mosselzaad, zoals vastgelegd met de blackbox.

Bij twijfel over het gebruik is het betreffende perceel of een gedeelte ervan in het monsterprogramma opgenomen.

In totaal zijn 526 stations bemonsterd tussen 12 januari en 19 februari 2018 door buitendienst medewerkers van de Waddenunit van het Ministerie van EZ vanaf de Rijksvaartuigen "Asterias" en "Phoca". Per station zijn 5 happen genomen met een Van Veen bodemhapper wat resulteert in een bemonsterd oppervlak van 0,276 $\mathrm{m}^{2}$ per station.

De vijf happen genomen per monsterstation zijn samengevoegd tot één monster voor het uitzoeken van mosselen, zeesterren en krabben. Per monsterstation is het volume (in liters) van de mosselen bepaald. Zeesterren en (strand)krabben zijn incidenteel in de bodemhappen aangetroffen en zijn daarom per station uit de vangst gehaald en als dagtotaal gewogen. Per dag zijn de vangsten aan mosselen bijeengevoegd. Stations met vooral mosselzaad als vangst zijn daarbij apart gehouden van stations met voornamelijk halfwas (schelplengte kleiner dan $45 \mathrm{~mm}$ ) en/of al voor consumptiegeschikte mosselen (schelplengte van minstens $45 \mathrm{~mm}$ ). Dit levert per dag dus twee verzamelmonsters op: zaad en meerjarige mosselen (halfwas + consumptie). Aan het eind van de dag is van elk daarvan het volume bepaald (in liters) en zijn eventueel deelmonsters genomen voor zaad $(3,5 \mathrm{I})$ en meerjarige mosselen $(6 \mathrm{I})$. De handleiding voor de verwerking van deze monsters is bijgevoegd in Bijlage $\mathbf{1}$.

\subsection{Berekeningen}

Bij de zaadvisserij maar ook bij het verzaaien van bijvoorbeeld halfwasmosselen naar Zeeland wordt gerekend in bruto gewichten - dit zijn mosselen inclusies tarra, zoals wier, pokken, zeesterren en schelpresten. Er zijn daarom ook bruto bestandsschattingen gemaakt.

Bij de doorrekening van netto naar bruto hoeveelheden zaad en meerjarige mosselen is uitgegaan van tarrapercentages van respectievelijk $40 \%$ en $25 \%$. Dit is conform de berekeningen bij bestandsopnamen van wilde mosselbestanden.

De volgende berekeningen zijn uitgevoerd, per grootteklasse mosselen $(i)$ en per dag (j):

- De subsample factor: $f=\mathrm{V}_{\mathrm{d}} / \mathrm{V}_{\mathrm{d} \_\mathrm{s}} * \mathrm{~V}_{\mathrm{s} \_\mathrm{s}}$ 
met $V_{d}$ als Volume mosselen per dag $(I), V_{d \_s}$ als Subsample uit $V_{d}(I)$ en $V_{s_{-} s}$ als Subsample uit $\mathrm{V}_{\mathrm{d} \_s}$ (aantal maal in gelijke delen).

- Totaal bemonsterde oppervlakte $\left(\mathrm{m}^{2}\right): O=S / A$ (Tabel 2.1)

- $\quad$ Totale mosselbiomassa $(\mathrm{kg})$ verzameld voor de verschillende grootteklassen (i): $T_{i}=\Sigma f_{j} * W_{j}$ met $w$ als verzamelgewicht mosselen $(\mathrm{kg})$

- Mosselbiomassa per vierkante meter $\left(\mathrm{kg} / \mathrm{m}^{2}\right): B_{i}=T_{i} / O$

- $\quad$ Mosselbiomassa percelen (Mkg): Bestand $=B_{i} * s^{*}$ grid/100 (Tabel 2.1)

- Totaal aantal mosselen verzameld: $N_{i}=\Sigma f_{j} * n_{j}$ met $n$ als aantal mosselen per station.

- Aantal mosselen per vierkante meter: $D_{i}=N_{i} / O$

- Individueel gewicht mosselen (g): $W_{i}=B_{i}^{*} 1000 / D_{i}$

Tabel 2.1 Parameters oppervlaktebepaling

\begin{tabular}{l|l|l|l}
\hline Parameter & Beschrijving & Eenheid & Waarde \\
\hline$s$ & Aantal bemonsterde stations & - & 527 \\
$A$ & Bemonsterde oppervlakte per station & $\mathrm{m}^{2}$ & 0,276 \\
grid & Oppervlakte per gridcel & ha & 8,26 \\
\hline
\end{tabular}




\section{Resultaten}

\subsection{Mosselbestand}

De aangetroffen dichtheden van mosselen zijn ruimtelijk weergegeven in Figuur 3.1. Een opsplitsing voor verschillende grootteklassen is bijgevoegd in Bijlage 2. De bijbehorende bestandsgroottes zijn, samen met de resultaten uit voorgaande jaren, samengevat in Tabel $\mathbf{3 . 1}$.

Het mosselbestand op de percelen in de Waddenzee begin februari 2018 is geschat op 50,4 miljoen kg ( 504.000 mosselton, $1 \mathrm{mt}=100 \mathrm{~kg}$ ) netto versgewicht. Daarvan bestaat 20,8 miljoen $\mathrm{kg}$ uit mosselzaad (broedval 2016). Van de 29,6 miljoen kg meerjarige mosselen bestaat 20,2 miljoen kg uit halfwas mosselen (schelplengte kleiner dan $45 \mathrm{~mm}$ ) en 9,3 miljoen $\mathrm{kg}$ uit consumptie mosselen (schelplengte van minstens $45 \mathrm{~mm}$ ). Uitgaande van tarrapercentages van $40 \%$ en $25 \%$ voor respectievelijk mosselzaad en meerjarige mosselen komt de bruto mosselbiomassa op de percelen uit op 74,1 miljoen kg (741.000 mt) versgewicht, waarvan 34,6 miljoen kg mosselzaad en 39,5 miljoen $\mathrm{kg}$ meerjarige mosselen.

Tabel 3.1. Het mosselbestand op mosselkweekpercelen in de Waddenzee vanaf 2004. Bij de omrekening van netto naar bruto hoeveelheden is voor mosselzaad en meerjarige mosselen uitgegaan van een tarrapercentage van resp. 45\% en $25 \%$. 1 Mosselton $(\mathrm{mt})=100 \mathrm{~kg}$. De gegevens tot en met 2011 zijn afkomstig uit (De Mesel \& Wijsman, 2011) en (Wijsman \& Jol, 2012).

\begin{tabular}{|c|c|c|c|c|c|c|c|c|}
\hline \multirow{2}{*}{$\begin{array}{l}\text { Mosselbestand } \\
\text { kweekpercelen } \\
\text { Waddenzee }\end{array}$} & \multicolumn{4}{|c|}{ Netto bestand (miljoen kg) } & \multicolumn{4}{|c|}{ Bruto bestand (mt x 1000) } \\
\hline & Zaad & $\begin{array}{l}\text { Halfwas } \\
(<45 \mathrm{~mm})\end{array}$ & $\begin{array}{c}\text { Groot } \\
(\geq 45 \mathrm{~mm})\end{array}$ & Totaal & Zaad & $\begin{array}{l}\text { Halfwas } \\
(<45 \mathrm{~mm})\end{array}$ & $\begin{array}{c}\text { Groot } \\
(\geq 45 \mathrm{~mm})\end{array}$ & Totaal \\
\hline $2004-\mathrm{dec}$ & 1,0 & 15,2 & 31,9 & 48,1 & 17 & 203 & 425 & 644 \\
\hline 2005 & 8,9 & 0,9 & 5,2 & 14,9 & 148 & 12 & 69 & 228 \\
\hline 2006 & 1,0 & 5,8 & 29,0 & 35,8 & 17 & 77 & 387 & 481 \\
\hline 2007 & 17,5 & 2,5 & 15,3 & 35,3 & 291 & 33 & 204 & 528 \\
\hline 2008 & 11,8 & 2,1 & 15,8 & 29,7 & 196 & 28 & 211 & 435 \\
\hline 2009 & 15,4 & 2,8 & 28,3 & 46,5 & 257 & 38 & 377 & 672 \\
\hline 2010 & 7,6 & 11,0 & 28,9 & 47,5 & 127 & 147 & 385 & 659 \\
\hline $2011-\mathrm{dec}$ & 8,9 & 1,3 & 11,8 & 21,9 & 148 & 17 & 157 & 322 \\
\hline $2013-$ jan & 39,6 & 1,5 & 5,6 & 46,7 & 660 & 20 & 74 & 754 \\
\hline 2013 - april & 52,5 & 1,7 & 4,7 & 58,9 & 875 & 23 & 62 & 960 \\
\hline $2013-$ dec & 14,3 & 31,1 & 4,7 & 50,1 & 238 & 415 & 63 & 716 \\
\hline 2014 - juli & 7,5 & 33,3 & 20,3 & 61,1 & 124 & 444 & 271 & 840 \\
\hline $2014-\mathrm{dec}$ & 37,7 & 7,6 & 13,4 & 58,7 & 629 & 101 & 179 & 909 \\
\hline 2015 - juni & 40,7 & 11,7 & 13,5 & 65,8 & 678 & 155 & 180 & 1013 \\
\hline $2015-\mathrm{dec}$ & 45,6 & 9,5 & 12,4 & 67,5 & 761 & 126 & 165 & 1052 \\
\hline 2016 - juni & 62,6 & 21,3 & 15,2 & 99,1 & 1044 & 284 & 202 & 1530 \\
\hline $2017-\mathrm{feb}$ & 48,1 & 14,6 & 9,1 & 71,8 & 802 & 195 & 121 & 1118 \\
\hline 2017 - juli & 80,3 & 20,4 & 18,0 & 118,8 & 1339 & 272 & 240 & 1851 \\
\hline $2018-f e b$ & 20,8 & 20,2 & 9,3 & 50,4 & 346 & 270 & 394 & 741 \\
\hline gem. winter '04-'17] & 19,8 & 8,1 & 16,2 & 44,2 & 330 & 109 & 217 & 655 \\
\hline
\end{tabular}




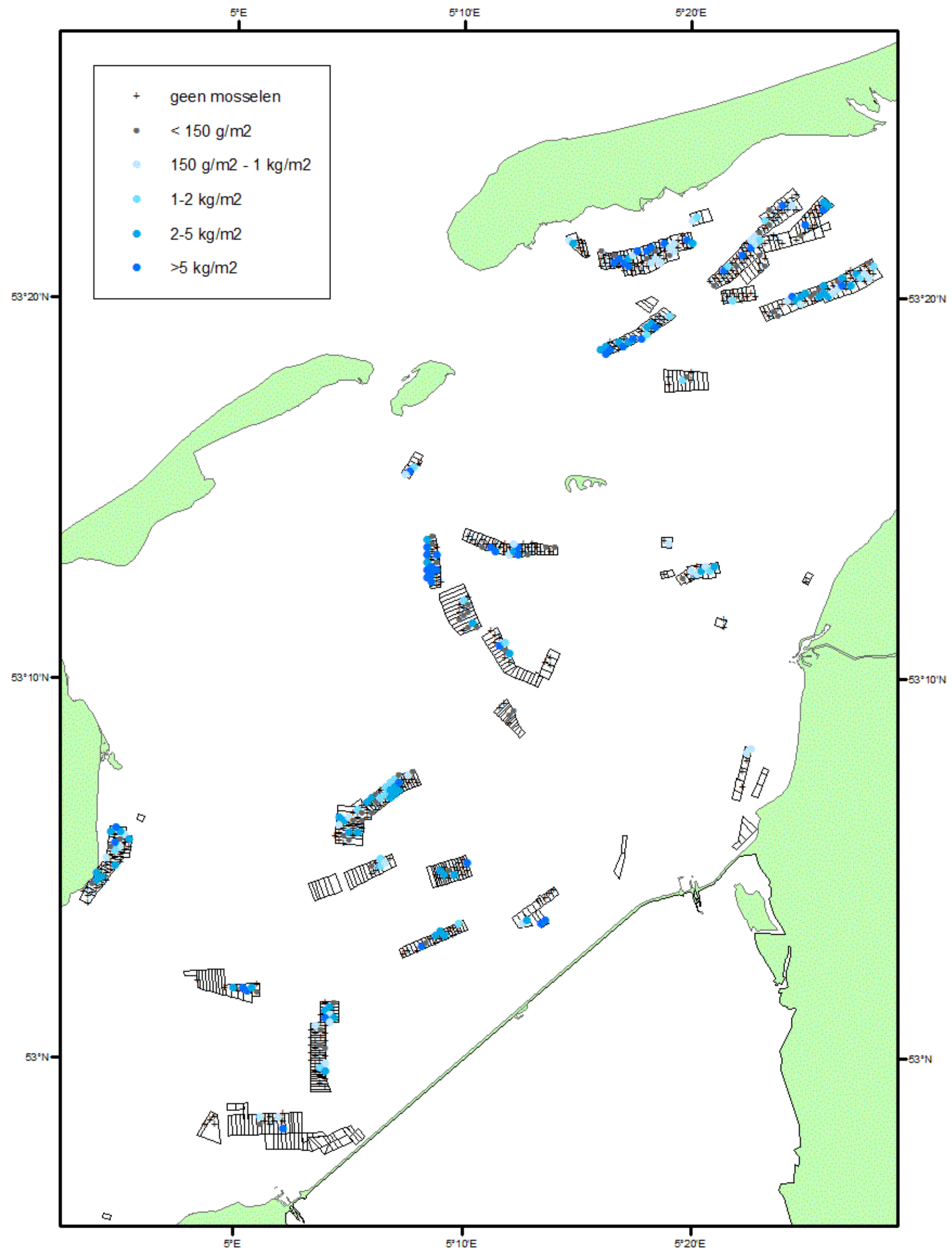

Figuur 3.1 Dichtheid van mosselen op mosselkweekpercelen in de Waddenzee in januari-februari 2018 in gram versgewicht per $\mathrm{m}^{2}$. 


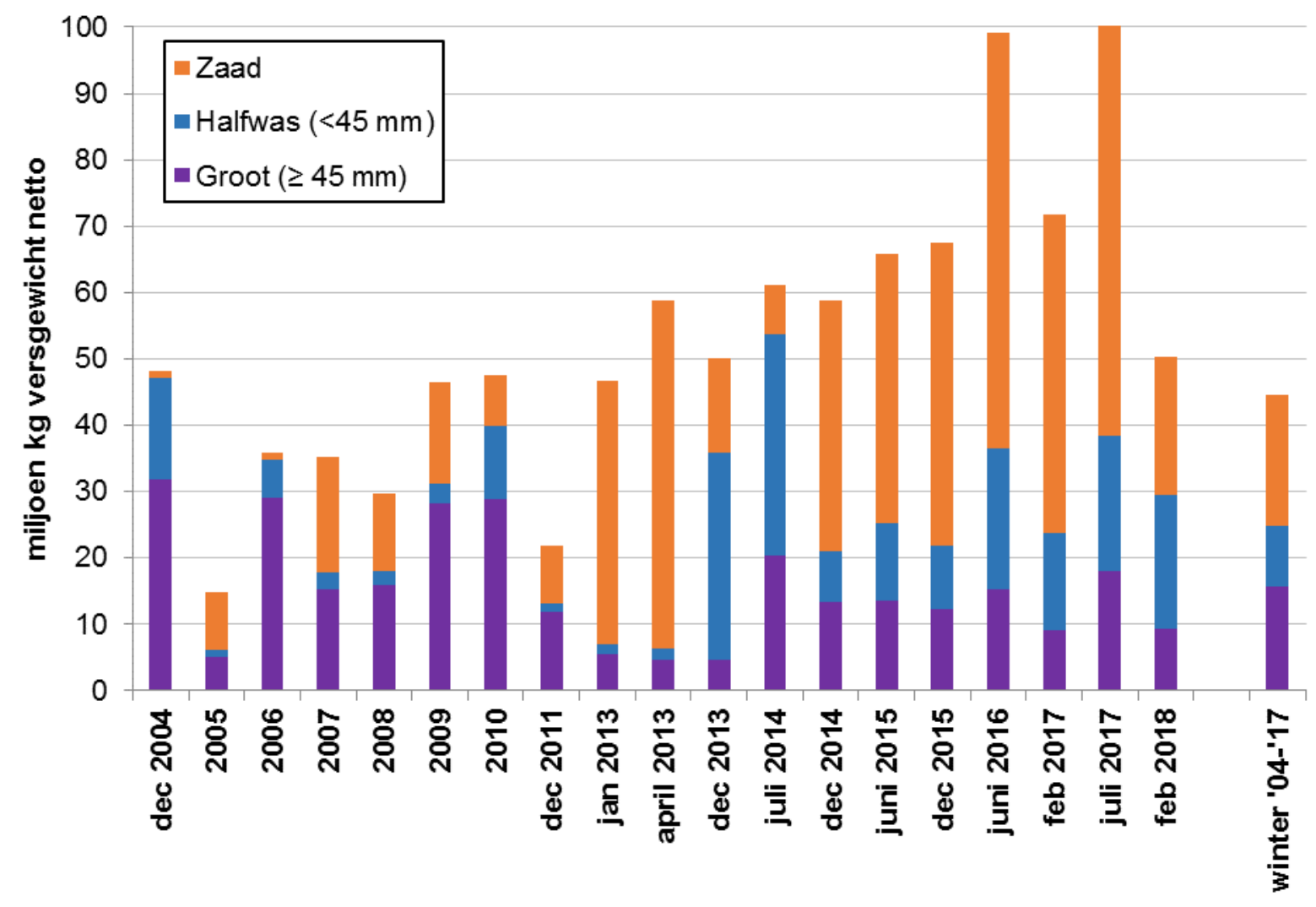

Figuur 3.2 Mosselbestand in miljoen kg netto versgewicht op mosselkweekpercelen in de Waddenzee in de periode december 2004 - februari 2018 met meest rechts de gemiddelde biomassa in de winters van 2004 - 2017. De mosselen zijn onderverdeeld in mosselzaad en meerjarige mosselen groter en kleiner dan 45 mm. De onderliggende gegevens zijn opgenomen in Tabel 3.1.

\subsection{Zeesterren en krabben}

In Tabel 3.2 zijn de gemiddelde dichtheden en biomassa's van zeesterren (Asterias rubens) en krabben (Carcinus maenas) vanaf 2013 weergegeven. Het gemiddelde individuele gewicht van zeesterren in krabben is toegenomen (Figuur 3.4B). Het bestand van zeesterren en de dichtheid op de percelen (Figuur 3.4A/C) is echter afgenomen ten opzichte van de winter van 2016/17 en zomer van 2017. Het bestand aan krabben op de percelen is relatief constant. Het voorkomen van zeesterren laat in tegenstelling tot het voorkomen van krabben een (positieve) relatie zien met het mosselbestand (Figuur 3.3). 
Tabel 3.2. Ontwikkeling van het bestand aan zeesterren en krabben groter dan $2 \mathrm{~cm}$ op kweekpercelen in de Waddenzee in de periode januari 2013 - juli 2017. IW = individueel gewicht. In januari 2013 zijn alleen de zeesterren bemonsterd.

\begin{tabular}{|c|c|c|c|c|c|c|c|c|}
\hline \multirow{3}{*}{$\begin{array}{l}\text { Predatoren op } \\
\text { percelen } \\
\text { Waddenzee }\end{array}$} & \multicolumn{4}{|c|}{ Zeesterren } & \multicolumn{4}{|c|}{ Krabben } \\
\hline & \multicolumn{2}{|c|}{ dichtheid } & \multirow{2}{*}{$\begin{array}{l}I W \\
\mathrm{~g}\end{array}$} & \multirow{2}{*}{$\begin{array}{l}\text { bestand } \\
\text { milj.kg }\end{array}$} & \multicolumn{2}{|c|}{ dichtheid } & \multirow{2}{*}{$\begin{array}{l}I W \\
\mathrm{~g}\end{array}$} & \multirow{2}{*}{$\begin{array}{l}\text { bestand } \\
\text { milj.kg }\end{array}$} \\
\hline & $n / m^{2}$ & $\mathrm{~g} / \mathrm{m}^{2}$ & & & $n / m^{2}$ & $\mathrm{~g} / \mathrm{m}^{2}$ & & \\
\hline 2013 - jan & 0,158 & 3,73 & 23,6 & 0,134 & & & & \\
\hline $2013-a p r$ & 0,152 & 2,99 & 19,6 & 0,076 & 0,621 & 10,07 & 16,2 & 0,257 \\
\hline $2013-d e c$ & 0,709 & 7,43 & 10,5 & 0,291 & 0,709 & 5,99 & 8,4 & 0,235 \\
\hline 2014 - juli & 0,448 & 9,93 & 22,2 & 0,345 & 0,904 & 11,93 & 13,2 & 0,415 \\
\hline $2014-d e c$ & 0,178 & 6,62 & 37,2 & 0,245 & 1,116 & 16,79 & 15,0 & 0,621 \\
\hline 2015 - juni & 0,229 & 7,77 & 33,9 & 0,294 & 0,736 & 9,23 & 12,5 & 0,349 \\
\hline $2015-d e c$ & 0,725 & 20,63 & 28,5 & 0,784 & 0,922 & 13,01 & 14,1 & 0,494 \\
\hline 2016 - juni & 2,815 & 12,12 & 4,3 & 0,453 & 0,840 & 9,50 & 11,3 & 0,356 \\
\hline $2017-f e b$ & 0,605 & 10,48 & 17,3 & 0,430 & 1,159 & 8,66 & 7,5 & 0,356 \\
\hline $2017-$ juli & 1,290 & 30,14 & 23,4 & 1,167 & 0,773 & 11,84 & 15,3 & 0,459 \\
\hline $2018 \mathrm{feb}$ & 0,248 & 6,51 & 26,3 & 0,283 & 0,474 & 7,93 & 16,7 & 0,345 \\
\hline gem winter '13-17' & 0,437 & 9,23 & 23,9 & 0,361 & 0,876 & 10,48 & 12,4 & 0,410 \\
\hline gem alle waarn. & 0,674 & 10,46 & 22,4 & 0,409 & 0,817 & 10,37 & 13,0 & 0,389 \\
\hline
\end{tabular}
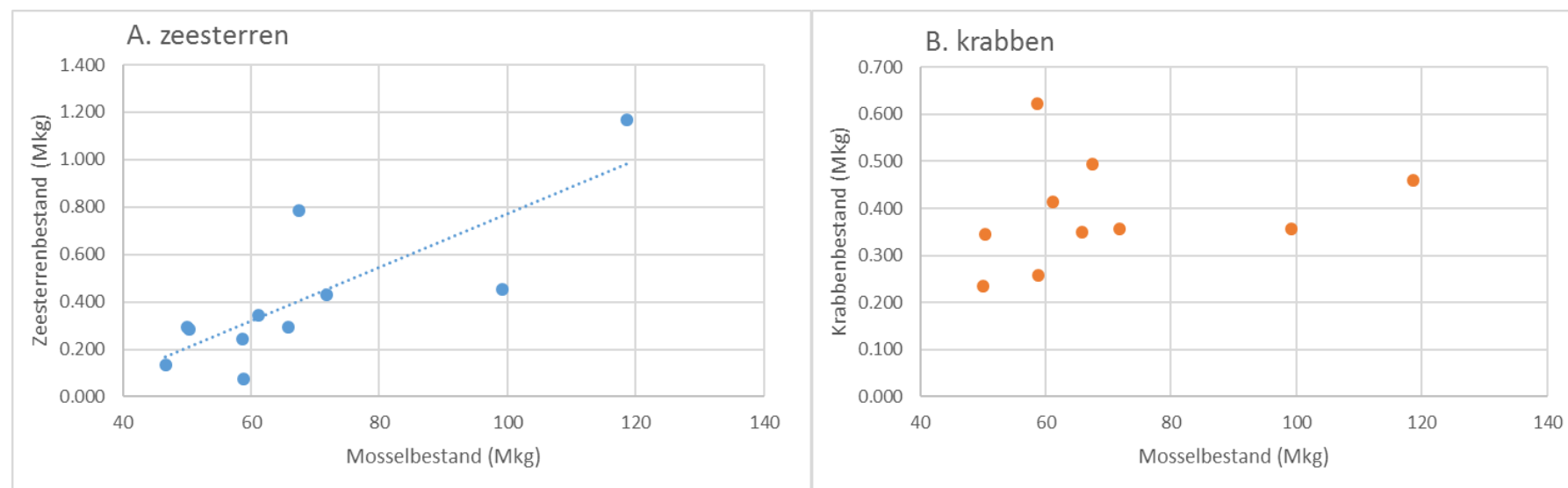

Figuur 3.3 Correlatie tussen het mosselbestand met $\mathbf{A}$. bestand aan zeesterren $\left(R^{2}=0.64\right)$, B bestand aan krabben $\left(R^{2}=0.05\right)$. 


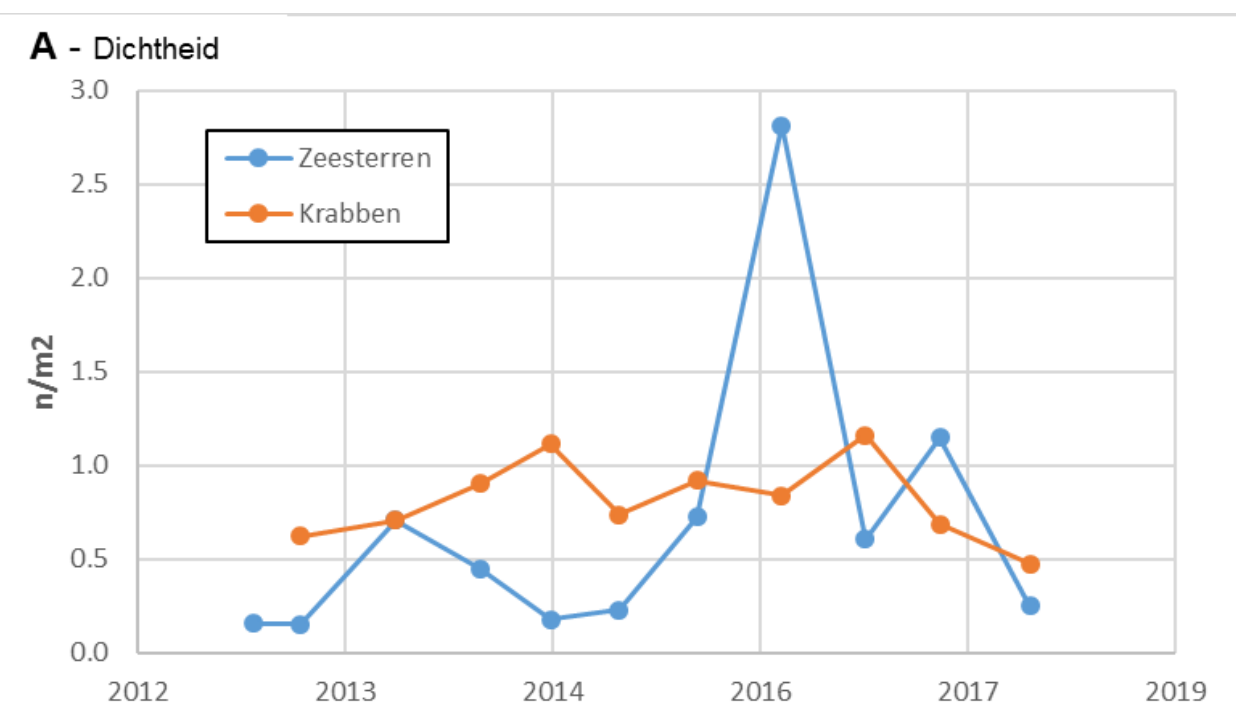

B - Individueel gewicht
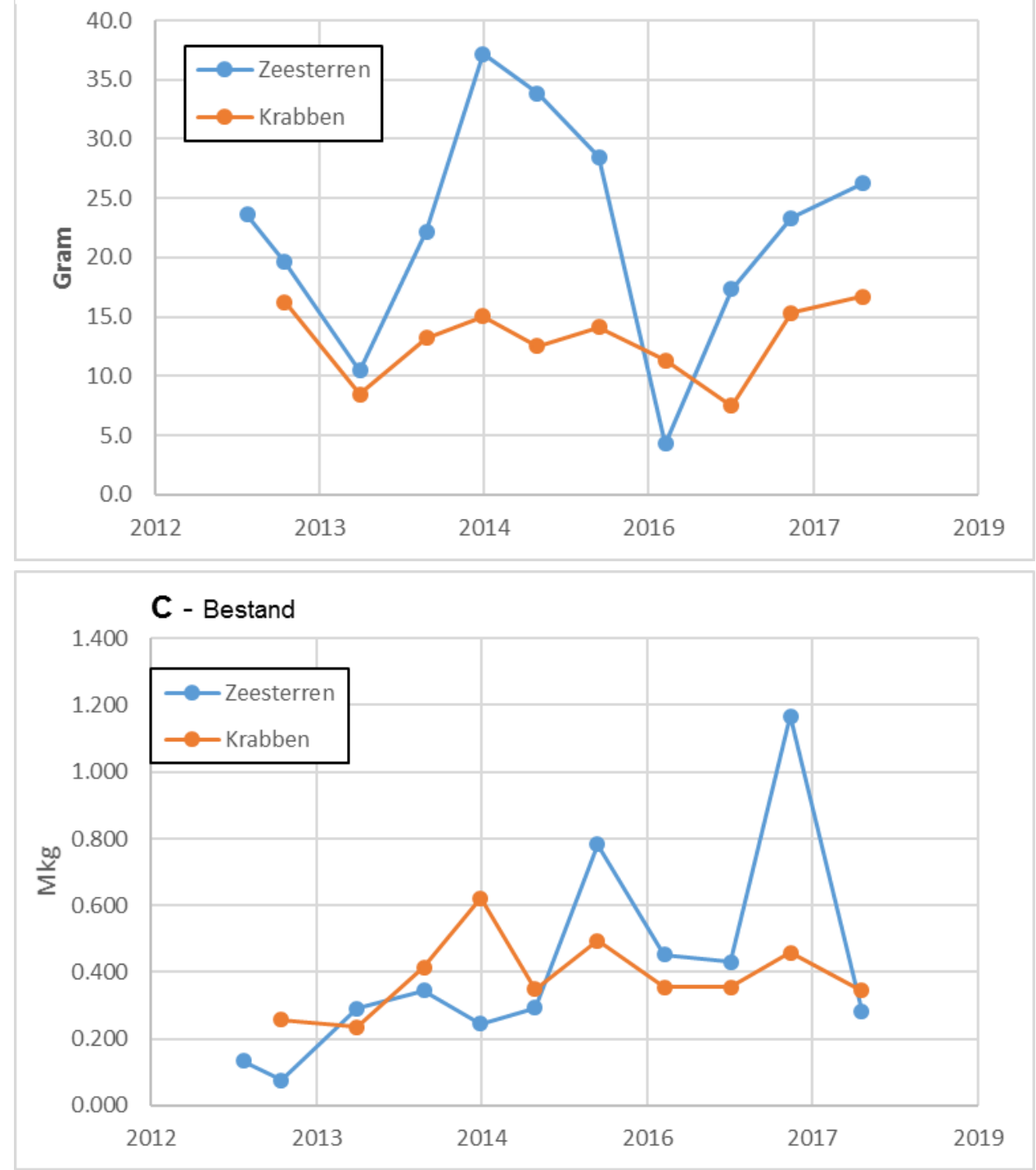

Figuur 3.4 Aanwezigheid van zeesterren en krabben (carapaxbreedte $>2 \mathrm{~cm}$ ) op mosselkweekpercelen in de Waddenzee in de periode 2013 - 2017. De onderliggende gegevens zijn opgenomen in Tabel 3.2; A: gemiddelde dichtheid in aantal per $\mathrm{m}^{2}$, B: gemiddeld gewicht per individuele zeester of krab in gram versgewicht, C: bestand aan zeesterren en krabben op de kweekpercelen in miljoen $\mathrm{kg}$ versgewicht. 


\section{$4 \quad$ Discussie en conclusie}

In juni 2017 is met 119 miljoen kg het hoogste mosselbestand op de percelen gevonden sinds het begin van de metingen in 2004. Het grootste deel van het bestand in juni 2017 bestond uit zaad ( 80 miljoen kg), daar is met de MZI oogst van 2017 nog eens 16 miljoen kg bijgekomen (Capelle et al., 2018). In de winter van 2017/2018 bleek van dit bestand nog 50 miljoen kg over: 20 miljoen kg zaad, 20 miljoen $\mathrm{kg}$ halfwas en 10 miljoen $\mathrm{kg}$ consumptie mosselen.

Als onderdeel van de vergunningverlening voor de mosselzaadvisserij in het voorjaar van 2017 is berekend dat in het najaar van 2017 een bestand van minimaal 48 miljoen kg netto aanwezig dient te zijn (van Stralen, 2017). De bemonstering heeft 2 maanden na het ijkmoment van 1 december plaats gevonden. In de tussenliggende 2 maanden zal het bestand op de percelen naar verwachting zijn afgenomen omdat 1 ) er geen mosselen zijn bijgekomen: mosselzaadvisserij heeft niet plaatsgevonden en er is geen MZI-zaad op de percelen uitgezaaid, 2) er nog wel mosselen naar Zeeland worden afgevoerd: naar de veiling of om te worden uitgezaaid op percelen in de Oosterschelde en 3) mosselbestanden in de winter van nature afnemen omdat de groei gering is terwijl de sterfte van mosselen doorgaat o.a. door predatie door eidereenden en zeesterren en als gevolg van stormen (o.a. op 3 januari en 18 januari). Dit betekent dat 50,4 $\mathrm{Mkg}$ een onderschatting is van de biomassa die op het ijkmoment 1 december 2017 aanwezig was en dat ervan uit gegaan kan worden dat de minimale hoeveelheid van 48 miljoen $\mathrm{kg}$ netto op 1 december 2017 op de percelen lag.

De patronen in de bestanden van krabben en zeesterren op de percelen, laten zien dat het bestand aan krabben minder door het mosselbestand beïnvloed wordt dan de populatie zeesterren. Het merendeel van de krabben zal ook niet op de mosselen foerageren, omdat mosselconsumptie door krabben sterk bepaald wordt door de relatie tussen de grootte van de krab en de grootte van de mossel (Murray et al., 2007). De grootste impact hebben krabben daarom op fijn mosselzaad. Zeesterren lijken veel minder belemmerd te worden door de grootte van de mosselen (Agüera, 2015). 


\section{$5 \quad$ Kwaliteitsborging}

Wageningen Marine Research beschikt over een ISO 9001:2008 gecertificeerd

kwaliteitsmanagementsysteem (certificaatnummer: 187378-2015-AQ-NLD-RvA). Dit certificaat is geldig tot 15 september 2018. De organisatie is gecertificeerd sinds 27 februari 2001. De certificering is uitgevoerd door DNV Certification B.V. 


\section{Literatuur}

Agüera A (2015) The role of starfish (Asterias rubens L.) predation in blue mussel (Mytilus edulis L.) seedbed stability, PhD dissertation. Wageningen University, Wageningen.

Capelle JJ, Blanco Garcia A, van Stralen MR (2018) Invang van mosselzaad aan MZI's; Resultaten 2017. Wageningen Marine Research Wageningen UR (University \& Research centre), Yerseke.

De Mesel I, Wijsman JWM (2011) Bestandsschatting mosselen op percelen in de Oosterschelde (1992-2009) en de Waddenzee (2004-2009). Yerseke.

EZ (2014) Nb-wet vergunning voor de mosselzaadvisserijen, 2015-2017. Kenmerk DGAN-NB / 15108373. Den Haag.

Murray LG, Seed R, Jones T (2007) Predicting the impacts of Carcinus maenas predation on cultivated Mytilus edulis beds. Journal of Shellfish Research, 26, 1089-1098.

Van Stralen MR (2015) Passende Beoordeling van de mosselvisserij in het sublitoraal van de Westelijke Waddenzee in de periode 2015 - 2017. MarinX, Scharendijke.

van Stralen MR (2017) Bijlage bij het Visplan mosselzaadvisserij voorjaar 2017; Doorrekening VKA model voorjaar 2017. Marinx, Scharendijke.

Wijsman JWM, Jol J (2012) Onderzoeksproject Duurzame Schelpdiervisserij (PRODUS). Deelproject $1 \mathrm{~A}$. Bepaling bestand op de mosselpercelen in de Waddenzee najaar 2011 (Mussel stock assessment on culture plots in the Waddensea in autumn 2012, report in Dutch). Wageningen IMARES, Yerseke, pp. 48. 


\section{Verantwoording}

Rapport C027/18

Projectnummer: 4313200007-07 KOMPRO 1

Dit rapport is met grote zorgvuldigheid tot stand gekomen, De wetenschappelijke kwaliteit is intern getoetst door een collega-onderzoeker en het verantwoordelijk lid van het managementteam van Wageningen Marine Research

Akkoord:

Dr. V.L. Escaravage

Collega-onderzoeker

Handtekening:

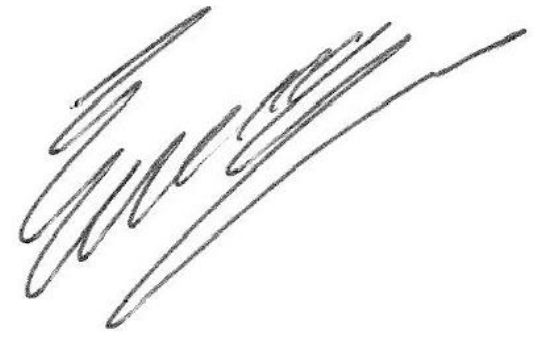

Datum:

17 april 2018

Akkoord:

Drs. J. Asjes

Manager Integratie

Handtekening:

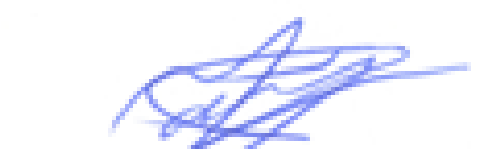

Datum:

17 april 2018 


\section{Bijlage 1 werkvoorschrift monstername}

\section{Handleiding bemonstering mosselpercelen}

versie 7 november 2014

\section{Monstername per station}

- Op elk station $\mathbf{5}$ happen

- Bij elkaar in een mand, spoelen

- Zeesterren uit de vangst halen, aantal noteren en bewaren in verzamel-emmer

- Idem voor krabben met schild groter dan $2 \mathrm{~cm}$ (duimnagel)

- Volume van de vangst bepalen in bekerglas. Aflezen in tienden liters. Wanneer het maar een paar mosselen zijn ("bewijsje") een "B" invullen. Wanneer er geen mosselen in de vangst zitten kan tarra over boord en is de vangst "nul".

- Bewaren in verzamelmand Zaad c.q. Halfwas + Cons. Bij mengsel indelen op dominante soort

- Aan dek: sample nummers ("treknummers" van die dag) invullen

- Brug: trek nummers noteren op de kaartjes.

Invullen meetliist aan dek

De blauwe waarden moeten worden ingevuld, hier als voorbeeld

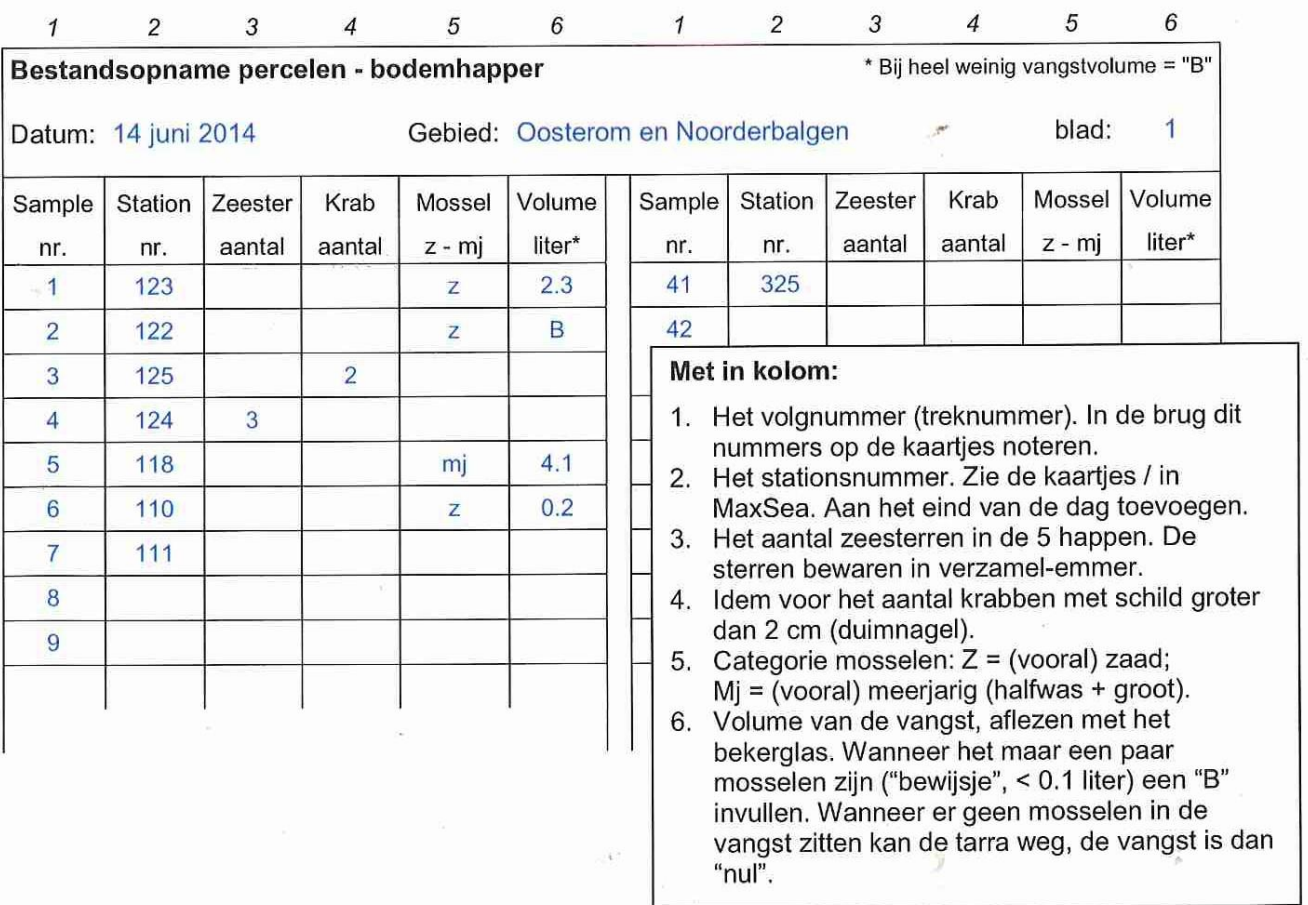


Uit de verzamelmanden wordt per dag een monster genomen en uitgezocht:

\section{Bepalen vangstvolume en het nemen van een subsample}

Van beide verzamelmanden vangstvolume bepalen in liters: grote zwarte emmer $=20$ liter, kleine zwarte emmer $=12$ liter of met maatbeker.

Volumes emmers graag nog even checken: Door de emmers met bekerglas te vullen met water.

- Vangst mengen en neem subsample op volume:

$>$ Zaad 3.5 liter $=1$ doorzichtig emmertje, uit "zaad" verzamel-mand

Meerjarig 6 liter $=$ wit emmertje, uit de andere mand

- Wanneer de vangst kleiner is dan 3.5 resp. 6 liter, dan de hele vangst als monster nemen.

\section{Uitzoeken subsamples}

Zie ook het voorbeeld zoals ingevulde tabel op volgende pagina

- Beide monsters liefst helemaal uitzoeken

- Uitzoeken op zaad, halfwas (= meerjarig en $<45 \mathrm{~mm}$ ) en groot ( = meerj. en $>45 \mathrm{~mm}$ )

- Ontpokken

- Mosselen tellen en wegen, de kapotte mosselen alleen tellen

- Pokken wegen

- Zeesterren en krabben: tellen en wegen

- $\mathrm{Bij}$ later wegen de mosselen, krabben en zeesterren bewaren in water in verband met vochtverlies. 


\section{Bijlage 2 Kaarten mosseldichtheid per grootteklasse}

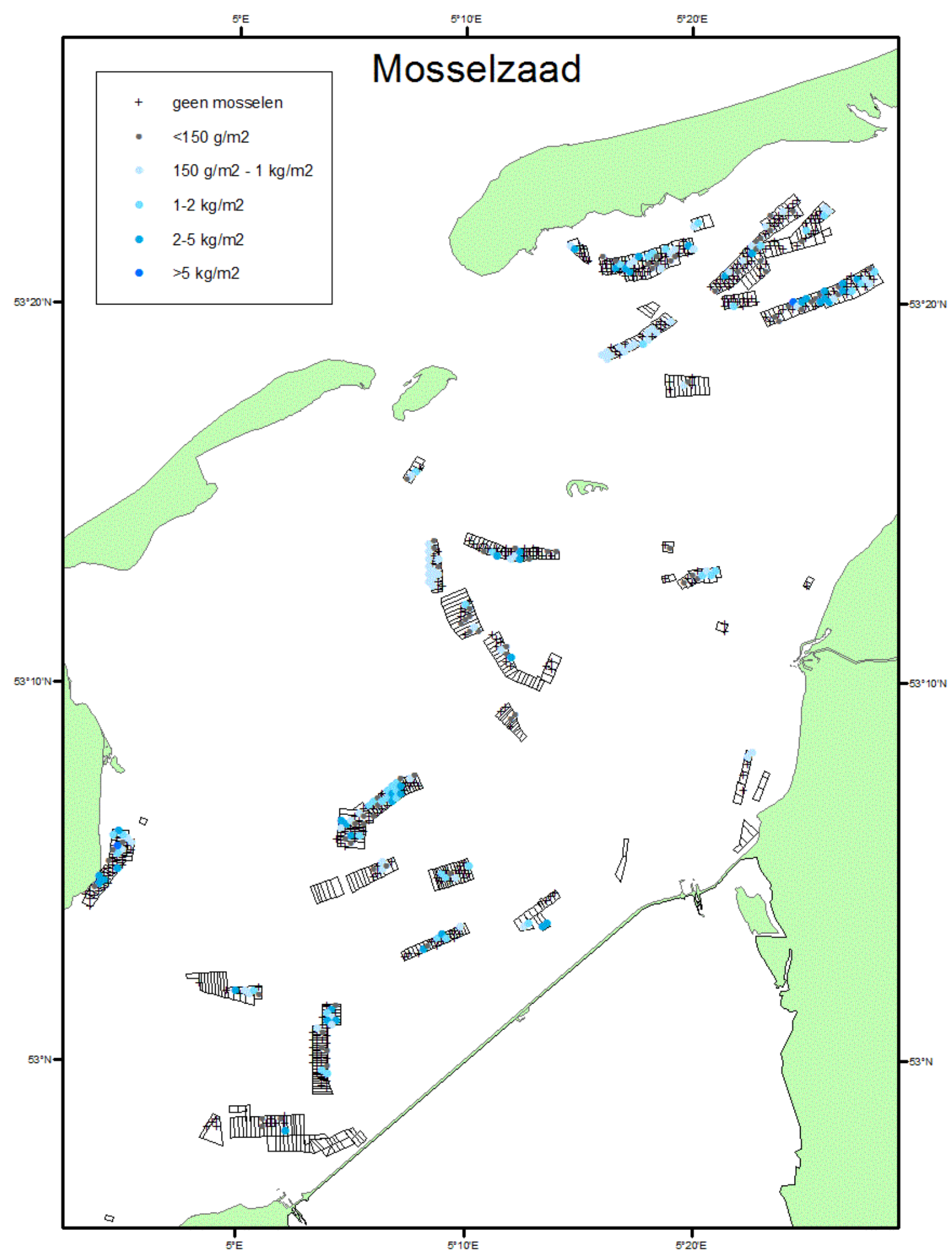




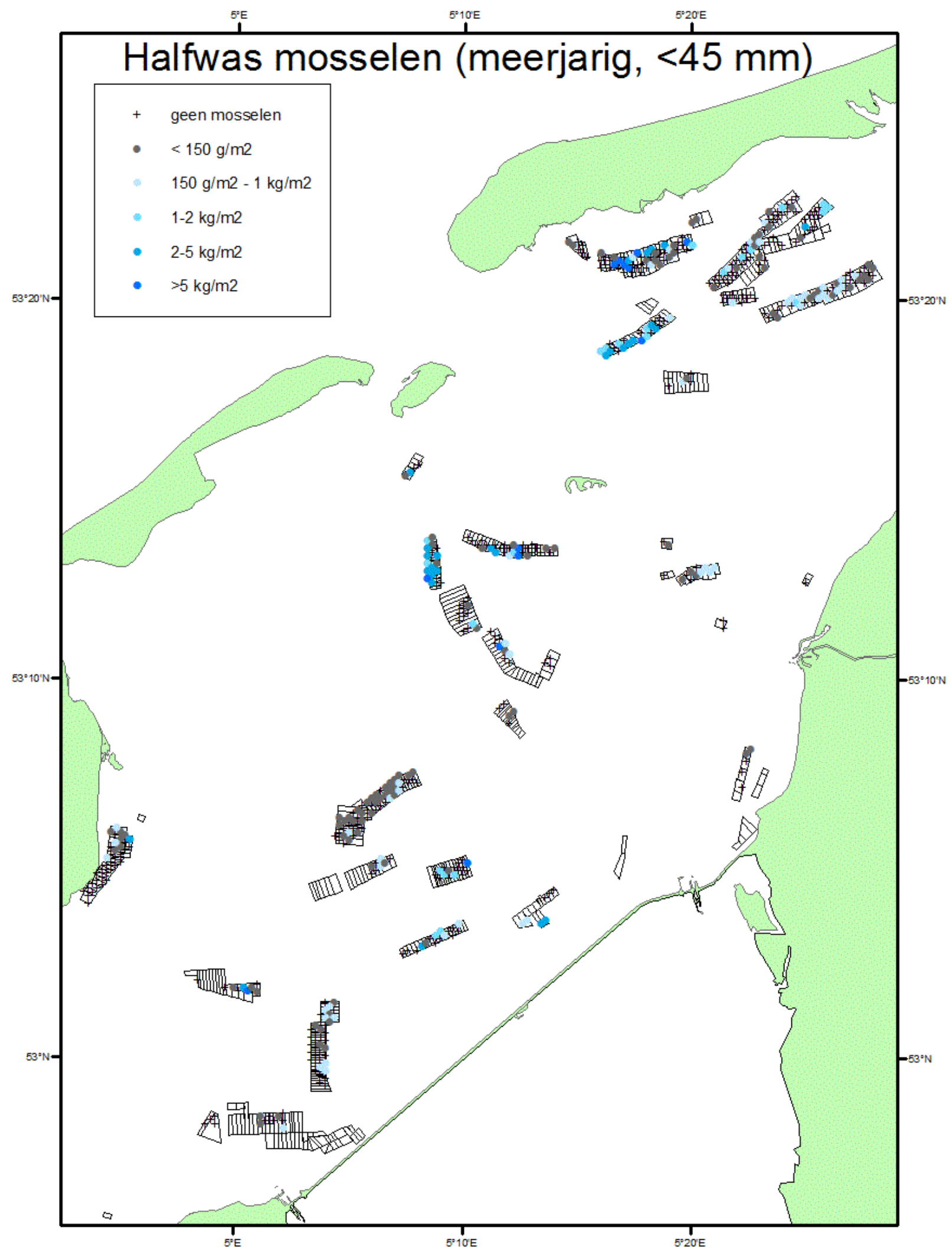




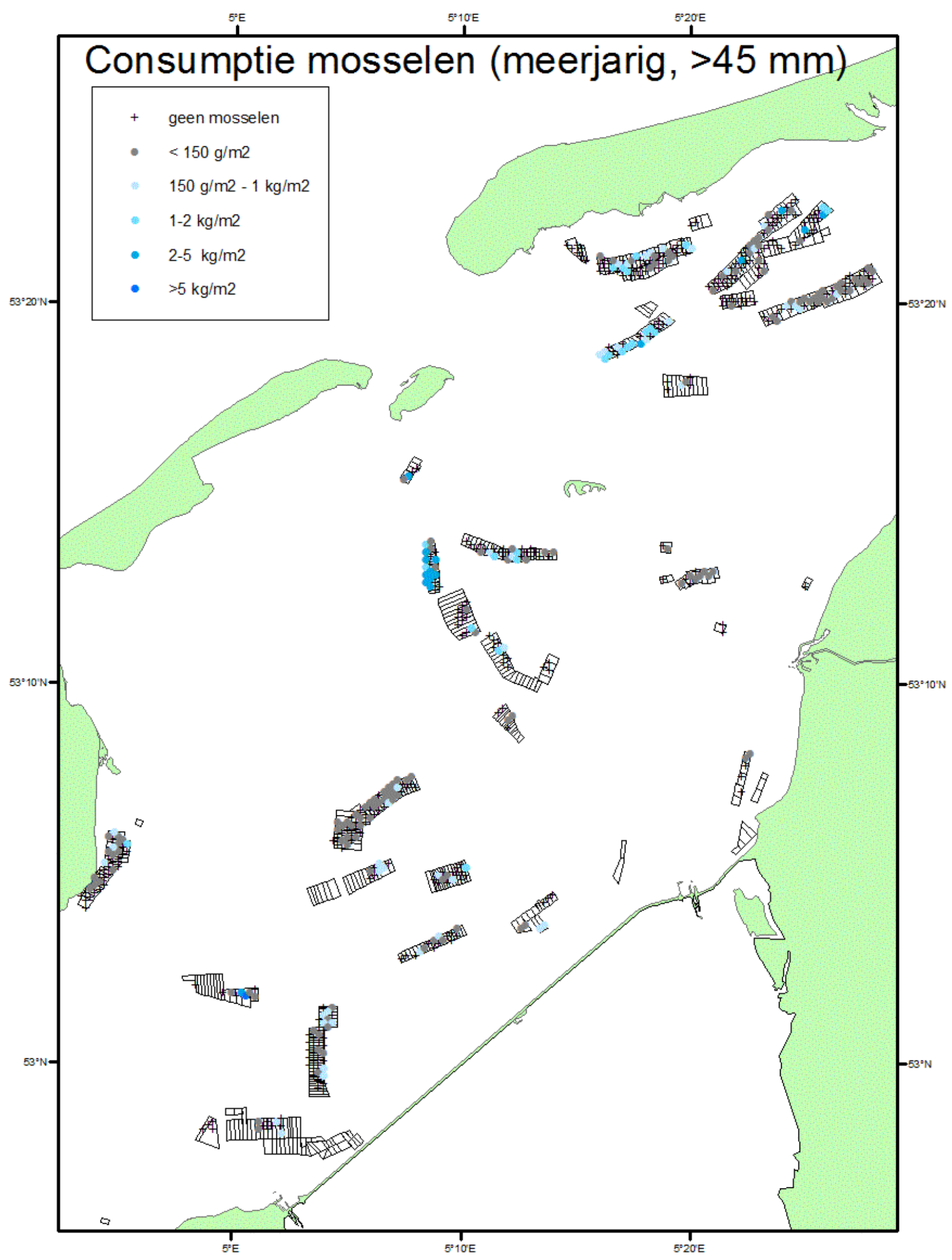


Wageningen Marine Research

T: +31(0)317480900

E: marine-research@wur,nl

www, wur, $\mathrm{nl} /$ marine-research

Visitors address

- Ankerpark 271781 AG Den Helder

- Korringaweg 7, 4401 NT Yerseke

- Haringkade 1, 1976 CP IJmuiden
Wageningen Marine Research is the Netherlands research institute established to provide the scientific support that is essential for developing policies and innovation in respect of the marine environment, fishery activities, aquaculture and the maritime sector,

Wageningen University \& Research is specialised in the domain of healthy food and living environment,

The Wageningen Marine Research vision:

'To explore the potential of marine nature to improve the quality of life,'

The Wageningen Marine Research mission

- To conduct research with the aim of acquiring knowledge and offering advice on the sustainable management and use of marine and coastal areas,

- Wageningen Marine Research is an independent, leading scientific research institute,

Wageningen Marine Research is part of the international knowledge organisation Wageningen UR (University \& Research centre), Within Wageningen UR, nine specialised research institutes of Stichting Wageningen Research (a Foundation) have joined forces with Wageningen University to help answer the most important questions in the domain of healthy food and living environment, 